1. MBBS, FCPS Ex PGT Obs/Gynae PIMS Hospital Islamabad.

2. MBBS, FCPS

Senior Registrar Obs/Gynae HITEC IMS.

3. MBBS, FCPS

Ex PGT Obs/Gynae PIMS Hospital Islamabad.

4. MBBS, FCPS

Senior Registrar Obs/Gynae HITEC IMS.

5. MBBS, FCPS

Assistant Professor Obs/Gynae HITEC IMS.

6. MBBS, FCPS

Senior Registrar Obs/Gynae HITEC IMS.

Correspondence Address:

Dr. Asia Nazir

Department of Obs/Gynae

PIMS Hospital Islamabad.

anam849@gmail.com

Article received on:

28/11/2019

Accepted for publication:

05/03/2020

\section{Comparison of subcutaneous sterile water injection versus normal saline water injection over the sacrum in females presenting with severe back pain undergoing normal vaginal delivery at term.}

\begin{abstract}
Asia Nazir' ${ }^{1}$, Adeela Ameen ${ }^{2}$, Shaista Naheed ${ }^{3}$, Tahira Jabeen ${ }^{4}$, Rukhsana Shaheen ${ }^{5}$, Tanzila Aftab ${ }^{6}$
ABSTRACT... Objectives: Compare the mean pain score with subcutaneous sterile water injection versus normal saline water injection over the sacrum in females presenting with severe back pain undergoing normal vaginal delivery at term. Study Design: Randomized Control Trial. Setting: MCH Centre, Pakistan Institute of Medical Sciences, Islamabad. Period: 21-08-2019 to 20-11-2019. Material \& Methods: The non-probability, consecutive sampling technique was used to include patients. In group A, patients injection was given 4 intracutaneous injections of $0.5 \mathrm{ml}$ sterile water in the lumbar- sacral region in the sitting position. One injection was given at the posterior superior iliac spine on both sides and second injection at $1 \mathrm{~cm}$ medial, and $1-2 \mathrm{~cm}$ inferior to the first point on both the sides using an insulin needle. These points overlie the area called Michaelis' rhomboid. In group B, patients were given injections of $0.5 \mathrm{ml}$ isotonic saline in the same region using an insulin needle. Then patients were followed-up for 90 minutes (1.5hours). After 90 minutes, pain on VAS was again measured. Results: In this study the mean pain score at baseline of the patient was $79.82 \pm 12.99$ and the mean pain score after the 90 minutes was $54.05 \pm 18.52$. Statistically there is highly significant difference was found between the study groups and pain after 90 minutes of the patients i.e. $p$-value $=0.000$ Conclusion: Our study results concluded that sterile water group patients showed better pain relief as compared to normal saline group in in females presenting with severe back pain undergoing normal vaginal delivery at term.
\end{abstract}

Key words: $\quad$ Back Pain, Female, Labor Pain, Normal Saline, Pain Relief, Sterile Water.

Article Citation: Nazir A, Ameen A, Naheed S, Jabeen T, Shaheen R, Aftab T. Comparison of subcutaneous sterile water injection versus normal saline water injection over the sacrum in females presenting with severe back pain undergoing normal vaginal delivery at term. Professional Med J 2020; 27(11):24882491. https://doi.org/10.29309/TPMJ/2020.27.11.4364

\section{INTRODUCTION}

A unique visceral pain is known as labor pain, it is associated with meaningful and wonderful life occasion regarding childbirth. ${ }^{1}$ It is a complex process experience individually and also changes during labor process. ${ }^{2}$

It arises due to stimulation of $\mathrm{C}$-afferent nerve fibers originates from uterine corpus and cervix. The fibers are terminated in the dorsal horn of the spinal segment $\mathrm{T} 10$ to $\mathrm{L} 1$ and causing visceral pain leads to lower back. Methods to reduce this pain are of major concern for the caregivers and mothers as well. The use of pharmacological methods is associated with increase mortality and morbidity for the mother and respiratory complications of the new born. For some women this approach may not be available because of need for specialized anesthetic service availability. ${ }^{3}$

The procedure is relatively simple and not technology dependent; may be a feasible and effective analgesic strategy is convenient for maternity model or a care setting. ${ }^{4}$

Previous trial are of the opinion that a dramatic and significant analgesic effect is recorded with sterile water injection on low back pain in cases during the labor lasts for 2.3 hours. Majority of women experienced a good analgesic effect by using sterile water injection when compared to those with placebo treatment. ${ }^{5} \mathrm{~A}$ randomized trial had reported that with sterile water injection $(n=50)$, the mean pain score was $49.3 \pm 33.96$ while 
with normal saline $(n=50)$ was $83.7 \pm 18.81$. The difference between both groups was significant $(P=0.000){ }^{1}$

This study was to compare the mean pain score with subcutaneous sterile water injection versus normal saline water injection over the sacrum in females presenting with severe back pain undergoing normal vaginal delivery at term. Literature has reported that with sterile water injection can be helpful in reducing severe lower back pain due to labor pains. But controversy exists in literature and there was no local study we observed in literature which can help us to implement the use of injection of sterile water to reduce the lower back pain. Because of severe lower back pain, often females anxiously choose cesarean section to be relieved from this pain. But this method can be helpful in reducing pain. So through this study we want to confirm whether sterile water injection is helpful in reducing pain as compared to normal saline injection or not.

\section{MATERIAL \& METHODS}

In this Randomized Controlled Trial at MCHCentre, Pakistan Institute of Medical Sciences, Islamabad we enrolled a total of 200 cases (100 in each group) where age range was 18-40 years, and all cases were at stage 1 (cervical dilatation $3 \mathrm{~cm}$ ) active labour pain $>3$ in 10 minutes, with severe back pain (VAS $\geq 60$ ). We excluded all cases 1 ) with multiple pregnancy, malpresentation (breech, transverse) and pharmacological analgesia prior to sterile water injection. Approval from hospital ethical committee was obtained before the start of study, a total of 200 females fulfilling the selection criteria were the part of this study. Routine informed consent of the participants was taken. After taking detailed demographic info (name, age, gestational age, parity), patients were screened for VAS score at baseline. Random allocation of patients to either group was done by lottery method. In group A, patients injection was given 4 intracutaneous injections of $0.5 \mathrm{ml}$ sterile water in the lumbar- sacral region in the sitting position. One injection was given at the posterior superior iliac spine (Point.1) on both sides and second injection at $1 \mathrm{~cm}$ medial, and 1-2 cm inferior to the first point on both the sides
(Point.2) using an insulin needle. These points overlie the area called Michaelis' rhomboid. In group B, patients were given injections of $0.5 \mathrm{ml}$ isotonic saline in the same region using an insulin needle. Then patients were followed-up for 90 minutes (1.5hours). After 90 minutes, pain on VAS was again measured. Data was collected on a standardized performa. Data analysis was done with the help of SPSS-18. Independent sample t-test was used to compare mean pain score in both groups.

\section{RESULTS}

In this present study total 200 cases were enrolled. The mean age of the patients was $28.18 \pm 6.48$ years with minimum and maximum ages of 18 \& 40 years respectively. Table-I

The study results showed that the mean pain score at baseline of the patient was $79.82 \pm 12.99$ with minimum and maximum pain values of $60 \&$ 100 respectively. Table-II

In this study the mean pain score after 90 minutes of the patient was $54.05 \pm 18.52$ with minimum and maximum pain values of $10 \& 95$ respectively. Table-III

\begin{tabular}{|c|c|c|c|c|c|}
\hline & & & 7 & & \\
\hline & & & an & & \\
\hline Age (y & ears) & & D & & \\
\hline & & & num & & \\
\hline & & & mum & & \\
\hline Tabl & -I. De & re & tistic & age (y & \\
\hline Stuc & y Gro & & $\mathbf{n}$ & Mean & SD \\
\hline Pain at & Ster & & 100 & 79.30 & 12.83 \\
\hline baseline & Norm & ine & 100 & 80.35 & 13.20 \\
\hline $\begin{array}{r}\text { Table-Il. } \\
\text { t-val }\end{array}$ & $\begin{array}{l}\text { Comp } \\
\mathrm{e}=-0\end{array}$ & $\begin{array}{r}\text { of } \\
\text { g } \\
P .\end{array}$ & $\begin{array}{l}\text { at } k \\
\text { ps. } \\
\mu e=0\end{array}$ & $\begin{array}{l}\text { line in } \\
\text { Insignif }\end{array}$ & $\begin{array}{l}\text { h study } \\
\text { ht) }\end{array}$ \\
\hline Stud & y Gro & & $\mathbf{n}$ & Mean & SD \\
\hline Pain at 90 & Ster & & 100 & 42.60 & 15.25 \\
\hline minutes & Norn & & 100 & 65.50 & 13.86 \\
\hline Table-III. & Comp & ud & $\begin{array}{l}\text { n aft } \\
\text { roup }\end{array}$ & $0 \mathrm{minu}$ & n both \\
\hline t-valu & $e=-11$ & & alue $=$ & 0 (sign & ant) \\
\hline
\end{tabular}




\section{DISCUSSION}

In our study the mean pain score at baseline of the patient was79.82 \pm 12.99 and the mean pain score after 90 minutes was $54.05 \pm 18.52$.

In this study the mean value of pain at baseline in sterile water group patient was $79.30 \pm 12.83$ and in normal saline group the mean value was $80.35 \pm 13.20$. Similarly the mean value of pain after 90 minutes in sterile water group patients was $42.60 \pm 15.25$ and in normal saline group the mean value was $65.50 \pm 13.86$. Statistically there is highly significant difference was found between the study groups and pain after 90 minutes of the patients. i.e $p$-value $=0.000$. So according to our study sterile water group patients showed better pain reduction as compared to normal saline group patients. Some of the studies are discussed here which are supporting the results of our finding and some are in contrary.

A study by Labrecque et $\mathrm{al}^{6}$ reveal that sterile water injection group had less pain as compared to TENS group.

Meta-analysis and systematic reviews ${ }^{5,7}$ reported a significant reduced self-reported pain in SWI group versus controls. Authors are of the opinion that sterile water injection is an effective therapeutic modality while managing continuous back pain during the course of labour.

A randomized trial had reported that with sterile water injection $(n=50)$, the mean pain score was $49.3 \pm 33.96$ while with normal saline $(n=50)$ was $83.7 \pm 18.81$. The difference between both groups was significant $(P=0.000) .1$

Another study ${ }^{8}$ is evident that number of cases self-scoring at-least $4 / 10 \mathrm{~cm}$ less pain at 10,45 , and 90 mins after administration of sterile water injection, and recorded insignificant difference between subcutaneous sterile water and intracutaneous, but significantly majority of the cases had sterile water (about 50\% to 60\%) than with placebo (20\% to $25 \%$ ).

Intracutaneous injections of sterile water in the skin over the sacrum have been shown to relieve the pain of labour in open studies and in controlled prospective studies. ${ }^{9-11}$

All studies reported treatment group average pain intensity, six studies (Ader 1990; Bahasadri 2006; Martensson 1999; Saxena 2009; Trolle 1991; Wiruchpongsanon 2006)1,8-13 finding superiority of sterile water over saline, but this is of uncertain significance because the underlying distributions were not explicitly or convincingly shown to be normal, with the possible exception of Bahasadri 2006. ${ }^{13}$

On the other hand three studies ${ }^{11-12}$ reported no significant differences between sterile water and saline groups, however, these studies enrolled smaller sample size. However, in our study, subcutaneous injections were less painful during administration as compared to those with normal saline group.

\section{CONCLUSION}

Our study results concluded that sterile water group patients showed better pain relief as compared to normal saline group in in females presenting with severe back pain undergoing normal vaginal delivery at term.

\section{Copyright $\subseteq 05$ Mar, 2020.}

\section{REFERENCES}

1. Saxena KN, Nischal H, Batra S. Intracutaneous injections of sterile water over the secrum for labour analgesia. Indian journal of anaesthesia 2009; 53(2):169.

2. Lee N, Mirtensson LB, Homer C, Webster J, Gibbons $\mathrm{K}$, Stapleton $\mathrm{H}$, et al. Impact on Caesarean section rates following injections of sterile water (ICARIS): A multicenter randomized controlled trial. BMC Pregnancy Childbirth 2013; 13:105.

3. Hutton E, Kasperink M, Rutten M, Reitsma A, Wainman $B$. Sterile water injection for labour pain: a systematic review and meta-analysis of randomized controlled trials. BJOG: An International Journal of Obstetrics \& Gynecology 2009; 116(9):1158-66.

4. Lee N, Coxeter P, Beckmann M, Webster J, Wright V, Smith $\mathrm{T}$, et al. A randomized non-inferiority controlled trial of a single versus a four intradermal sterile water injection technique for relief of continuous lower back pain during labour. BMC pregnancy and childbirth 2011; 11(1):21. 
5. Fogarty V. Intradermal sterile water injections for the relief of low back pain in labour-A systematic review of the literature. Women and birth 2008; 21(4):157-63.

6. Labrecque M, Nouwen A, Bergeron M, Rancourt J-F. A randomized controlled trial of no pharmacologic approaches for relief of low back pain during labor. The Journal of family practice 1999; 48(4):259-63.

7. Mårtensson L, Wallin G. Sterile water injections as treatment for low-back pain during labour: A review. Australian and New Zealand journal of obstetrics and gynecology 2008; 48(4):369-74.

8. Måtensson L, Wallin G. Labour pain treated with cutaneous injections of sterile water: a randomized controlled trial. BJOG: An International Journal of Obstetrics \& Gynecology 1999; 106(7):633-7.

9. Ader L, Hansson B, Wallin G. Parturition pain treated by intracutaneous injections of sterile water. Pain 1990; 41(2):133-8.
10. Wiruchpongsanon P. Relief of low back labor pain by using intracutaneous injections of sterile water: a randomized clinical trial. Journal-medical association of thailand 2006; 89(5):571.

11. Trolle B, Møller M, Kronborg H, Thomsen S. The effect of sterile water blocks on low back labor pain. American journal of obstetrics and gynecology 1991; 164(5):1277-81.

12. Ader L, Hansson B, Wallin G. Injections of sterile water for labour pain. Nursing times 1991; 87(6):53.

13. Bahasadri S, Ahmadi-Abhari S, Dehghani-Nik M, Habibi GR. Subcutaneous sterile water injection for labour pain: A randomized controlled trial. Australian and New Zealand journal of obstetrics and gynecology 2006; 46(2):102-6.

\begin{tabular}{|c|c|c|c|}
\hline \multicolumn{4}{|c|}{ AUTHORSHIP AND CONTRIBUTION DECLARATION } \\
\hline Sr. \# & Author(s) Full Name & Contribution to the paper & Author(s) Signature \\
\hline 1 & Asia Nazir & Conceived main idea. & Aim \\
\hline 2 & Adeela Ameen & Article writing. & \\
\hline 3 & Shaista Naheed & Data collection. & Tahiva \\
\hline 4 & Tahira Jabeen & $\begin{array}{l}\text { Data collection, Manuscript } \\
\text { writing. }\end{array}$ & Ruleheare \\
\hline 5 & $\begin{array}{l}\text { Rukhsana Shaheen } \\
\text { Tanzila Aftab }\end{array}$ & $\begin{array}{l}\text { Data formalling. } \\
\text { Data analysis. }\end{array}$ & Sanjels \\
\hline
\end{tabular}

